\title{
Factors affecting the exchange of genetic material between Nordic and US Holstein populations
}

\author{
L. H. Buch,${ }^{*} \dagger^{1}$ A. C. Sørensen, $\dagger$ J. Lassen, $†$ P. Berg, $\dagger$ L. G. Christensen, ${ }^{*}$ and M. K. Sørensen $†$ \\ *Department of Large Animal Sciences, University of Copenhagen, Højbakkegård Allé 5, DK-2630 Taastrup, Denmark \\ †Department of Genetics and Biotechnology, University of Aarhus, Blichers Allé 20, PO Box 50, DK-8830 Tjele, Denmark
}

\begin{abstract}
The possibility of profitable cooperation between dairy cattle populations depends on several factors. Among these factors is the similarity of breeding goals, for example, as measured by the correlations between selection indices. Correlations between selection indices less than unity can usually be explained by differences in economic values, trait definitions, national genetic evaluation procedures, and genotype $\times$ environment interactions. The objective of this study was to test whether uniform definitions of the female fertility traits would increase the exchange of genes across populations, and to quantify the effect on genetic gain. A second objective was to test whether a more similar relative weighting of the index traits across populations would increase the exchange of genes across populations, and to quantify the effect on genetic gain. This was done in a stochastic simulation study of the Nordic and US Holstein populations. Uniform definitions of the female fertility traits did not increase total genetic gain in the Nordic Holstein population. The standardization did not seem to affect selection across populations either. However, the results were sensitive to the assumptions made in the simulation study, especially the genetic correlations between traits. A more similar relative weighting of the index traits across populations did not change total genetic gain in the Nordic Holstein population. The possibility of exchanging genetic material with the US Holstein population led to significantly higher progress in the aggregate genotype in the Nordic Holstein population compared with a situation in which exchange was not possible. Hence, importation of US Holstein genetics for use in the Nordic Holstein population is recommended. In addition, results indicated that population size is of greater importance than differences in trait definitions and relative weighting of the index traits for the advantage of exchanging genetic material between the Nordic and the US Holstein populations.
\end{abstract}

Received July 9, 2008.

Accepted April 24, 2009.

${ }^{1}$ Corresponding author: Line.HjortoBuch@agrsci.dk
The possibility of exchanging genetic material with the Nordic Holstein population did not change progress in the aggregate genotype in the US Holstein population compared with a situation in which exchange was not possible, but it tended to result in lower genetic progress in protein yield and greater genetic progress or smaller genetic declines in the functional traits. Thus, importation of genetic material from Nordic Holsteins may slow down the deterioration of animal health and reproduction in US Holsteins.

Key words: dairy cattle, female fertility, selection, breeding scheme simulation

\section{INTRODUCTION}

Cooperation between dairy populations offers the potential to select the best breeding animals across populations. Selection across populations should therefore always result in at least as much gain as selection within populations (Smith and Banos, 1991). The possibility of profitable cooperation depends on several factors: 1 ) number of populations, 2) sizes of the populations, 3) initial genetic means of the populations, and 4) similarity of the breeding goals, for example, as measured by the correlation between the selection indices (Smith and Banos, 1991). Several studies have shown that it is beneficial in the long term to select animals across populations if the correlation between selection indices is above 0.80 to 0.90 (Smith and Banos, 1991; Mulder and Bijma, 2006). Cooperation can, for instance, be a solution for minor dairy breeds to overcome the problems associated with a small population size, and it can decrease inbreeding within populations (Jørgensen and Sørensen, 2002). For large breeds, such as the Holstein breed, cooperation between populations can be beneficial because the required number of breeding animals can be selected from a larger global population. This results in higher selection intensity and thus in higher genetic gain (Mulder and Bijma, 2006).

Correlations between selection indices less than unity can usually be explained by differences in economic values, trait definitions, national genetic evaluation procedures, and genotype $\times$ environment $(\mathbf{G} \times \mathbf{E})$ 
interactions. $A \mathrm{G} \times \mathrm{E}$ interaction is said to occur when genotypes respond differently to changes in the environment and is present if the genetic correlation between the same trait measured in 2 environments is less than unity (Lynch and Walsh, 1998). It is, to some extent, possible to introduce uniform trait definitions, data recordings, and genetic evaluation procedures that will increase the correlation between selection indices. Standardization of trait definitions across countries already takes place. For instance, in many countries records on production traits and conformation traits are collected in internationally standardized programs approved by the International Committee for Animal Recording (2007) and the World Holstein Friesian Federation (2005), respectively. However, some functional traits (for instance, female fertility) are still described by means of a wide range of measurements (Jorjani, 2005).

Today, most dairy countries have introduced total merit indices in which functional traits as well as production traits are included. Breeding goals change over time, and the present tendency is to put relatively more weight on the functional traits (Miglior et al., 2005). Some functional traits of considerable economic value, that earlier were difficult to record in a practical situation, are now included in herd management systems and in national databases because of advances in data collection. In addition, huge improvements in computer power have facilitated the development of more appropriate genetic evaluation models for these traits. Female fertility is a complex trait that is difficult to define and measure, and in most countries, genetic evaluations have not been incorporated in the total merit indices until recently (Jorjani, 2006b). Genetic evaluations for female fertility were, however, available as early as the 1970s in some of the Nordic countries (Shook, 2006), and today the genetic evaluations are based on more traits measuring the ability of the cow both to re-cycle and to conceive. In the mid-1990s, several other European countries introduced genetic evaluations for female fertility, and in 2003, genetic evaluations based on days open were introduced in the United States (Shook, 2006). Interbull (2008) has provided international evaluations of fertility traits since February 2007. The international evaluation is complicated by the fact that female fertility is described by many different traits. Therefore, simple measurements taken separately that describe the ability of the cow to re-cycle or to conceive are recommended by Interbull (Jorjani, 2006b), as opposed to traits combining these 2 aspects of fertility. Days from calving to first insemination $(\mathbf{C F})$ is an example of a measurement that describes the ability of the cow to re-cycle, and confirmed conception rate, number of inseminations (NI), nonreturn rate, and days from first to last insemination $(\mathbf{F L})$ are examples of measurements that describe the ability of the cow to conceive. In time, some countries may change their current measurements to those recommended by Interbull because of advances in data collection and genetic evaluation.

The US Holstein breed has had a strong influence on the genetic makeup of the European black-and-white strains through exportation of semen and embryos. This exchange of genetic material still exists, and in recent years, the exportation of semen from Nordic Holstein bulls to the United States has begun.

The objective of this study was to test whether formulating uniform definitions of the female fertility traits would increase the exchange of genes across populations, and to quantify the effect on genetic gain. A second objective was to test whether a more similar relative weighting of the index traits across populations would increase the exchange of genes, and to quantify the effect on genetic gain.

\section{MATERIALS AND METHODS}

Two dairy cattle populations, each with an individual breeding program and environment, were simulated. Population 1 reflected the Swedish, Finnish, and Danish (here, the Nordic) Holstein population and population 2 reflected the US Holstein population. The populations were simulated using a modified version of the stochastic simulation program DairySim (Sørensen et al., 1999). Fifteen replicates of 4 scenarios, which are described below, were simulated, each covering a 25-yr period.

\section{Population Structure}

The 2 populations of females were each divided into 2 groups, a breeding population and a test population. In addition, the 2 populations of males were each divided into 2 groups, a group of test bulls and a group of proven bulls. Semen from proven bulls was used in the breeding populations, and semen from test bulls was used in the test populations. All test bulls were recruited from their own breeding population and tested in their own environment. No animals were moved from one environment to the other.

The breeding populations consisted of 32,000 cows in population 1 and 100,000 cows in population 2 . Females in the breeding populations were simulated individually and allocated to several equally sized herds. Herd size was 100 cows in population 1 and 200 cows in population 2 . True breeding values and phenotypes were simulated for base population animals based on the parameters in Table 1 . The phenotypes for protein 
Table 1. Heritabilities (on the diagonal), genetic correlations (above the diagonal), and phenotypic correlations (below the diagonal) for the traits in the simulation study ${ }^{1}$

\begin{tabular}{lrrrrrrrrrrrr}
\hline Trait & PY 1 & \multicolumn{1}{c}{ MA } & SCS 1 & \multicolumn{1}{c}{ NI 1 } & CF 1 & FL 1 & PY 2 & SCS 2 & DPR & NI 2 & CF 2 & FL 2 \\
\hline PY 1 & 0.27 & -0.30 & -0.18 & -0.54 & -0.40 & -0.42 & 0.90 & -0.18 & -0.31 & -0.41 & -0.33 & -0.39 \\
MA & 0.00 & 0.04 & 0.67 & 0.28 & 0.39 & 0.33 & -0.19 & 0.60 & 0.20 & 0.17 & 0.23 & 0.19 \\
SCS 1 & 0.06 & 0.22 & 0.13 & 0.17 & 0.21 & 0.17 & -0.18 & 0.88 & 0.20 & 0.15 & 0.18 & 0.15 \\
NI 1 & -0.09 & -0.01 & 0.00 & 0.05 & 0.47 & 0.82 & -0.42 & 0.15 & 0.70 & 0.85 & 0.36 & 0.69 \\
CF 1 & -0.05 & 0.02 & 0.03 & -0.03 & 0.05 & 0.47 & -0.33 & 0.18 & 0.70 & 0.36 & 0.85 & 0.42 \\
FL 1 & -0.06 & 0.02 & 0.02 & 0.80 & -0.06 & 0.02 & -0.38 & 0.15 & 0.70 & 0.69 & 0.42 & 0.85 \\
PY 2 & 0.23 & -0.02 & -0.03 & -0.05 & -0.04 & -0.03 & 0.25 & -0.22 & -0.35 & -0.40 & -0.35 & -0.45 \\
SCS 2 & -0.03 & 0.04 & 0.11 & 0.01 & 0.01 & 0.01 & 0.05 & 0.13 & 0.30 & 0.17 & 0.21 & 0.17 \\
DPR & -0.03 & 0.01 & 0.01 & 0.03 & 0.03 & 0.02 & -0.19 & 0.05 & 0.04 & 0.75 & 0.75 & 0.75 \\
NI 2 & -0.04 & 0.01 & 0.01 & 0.03 & 0.01 & 0.02 & -0.20 & 0.00 & 0.71 & 0.03 & 0.36 & 0.80 \\
CF 2 & -0.04 & 0.01 & 0.01 & 0.02 & 0.04 & 0.01 & -0.17 & 0.03 & 0.41 & 0.10 & 0.05 & 0.50 \\
FL 2 & -0.02 & 0.00 & 0.01 & 0.02 & 0.01 & 0.01 & -0.17 & 0.02 & 0.65 & 0.70 & -0.06 & 0.01 \\
\hline
\end{tabular}

${ }^{1}$ All traits are defined so higher values are favorable. $\mathrm{PY}=$ protein yield; $\mathrm{MA}=$ mastitis resistance; $\mathrm{NI}=$ number of inseminations; $\mathrm{CF}=$ days from calving to first insemination; $\mathrm{FL}=$ days from first to last insemination; DPR $=$ daughter pregnancy rate. $1=$ population $1 ; 2=$ population 2 .

yield were realized when the females had finished their first lactation at the age of 35 mo. Animals in the base populations were distributed among 8 age classes, and their phenotypes were allocated to herd-year-season groups. Animals in the base populations were randomly selected, whereas other animals were selected according to the highest total merit index as described in the Breeding Value Estimation section. Random mating of selected animals was applied, with the exception that parent-offspring matings and matings between full-sibs and half-sibs were not allowed, to avoid strong inbreeding. All heifers calved when they were 24 mo old, and the calving interval was $1 \mathrm{yr}$. All animals within each population calved at the same time of the year, but to reflect a realistic data structure, the cows were divided randomly between 4 different calving seasons within year and herd. Females in the breeding populations stayed in the herds until better replacement heifers were available within the herd or until they were randomly involuntarily culled. It was assumed that $15 \%$ of the cows were involuntarily culled per year. The females in the breeding populations were available until they reached the end of the sixth lactation.

The number of test bulls per year was 355 in population 1 and 1,100 in population 2 . The progeny tests were based on daughter group sizes of 125 in population 1 and 70 in population 2. Hence, test populations 1 and 2 consisted of 44,400 and 77,000 first-parity test bull daughters per year, respectively. Owing to computational limitations, females in the test populations were not simulated separately. Instead, all traits were simulated as twice the daughter yield deviations for each of the test bulls. All daughters in both test populations had observations for protein yield and SCS. For mastitis resistance, $90 \%$ of the daughters in test population 1 were measured, and for the fertility traits, $80 \%$ of the daughters in both test populations were measured. The phenotypes of the first-crop daughters were realized when the test bulls reached the age of 58 mo.

To reflect reality, a random sample of $15 \%$ of the bull calves from the breeding population died per year (Hansen, 2004). This was realized when the bull calves were 11 mo old. Immediately after, selection of test bulls was performed using screening of the breeding population. The selection was based on the average EBV of the parents. Test bulls were used for test inseminations at the age of $15 \mathrm{mo}$, and they were not used in the time period from the test inseminations until daughter performances were recorded. Selection of proven bulls was based on EBV and truncation as described in the Breeding Value Estimation section. Proven bulls were available until the age of $8 \mathrm{yr}$; thus, bulls could, at the maximum, achieve 4 insemination seasons. The number of live-born calves sired by a single bull within $1 \mathrm{yr}$ was set to 2,000 calves in breeding population 1 and 5,000 calves in breeding population 2. Thus, 16 and 20 proven bulls were selected each year and the selected proportions were 0.045 and 0.018 in populations 1 and 2 , respectively.

\section{Traits}

For population 1, the index traits were protein yield, mastitis resistance, SCS, NI, CF, and FL. Somatic cell score was not included in the total merit index but contributed information through the genetic correlation with mastitis resistance when breeding values for mastitis resistance were calculated. For population 2, the traits were protein yield, SCS, daughter pregnancy rate (DPR), NI, CF, and FL. All traits are defined so that higher values were desirable. Furthermore, all traits were simulated as normally distributed traits, and the 
Table 2. Economic values for breeding goals (BG) and total merit index (TMI) weights in US dollars per phenotypic standard deviation, with relative emphasis in percentage in parentheses.

\begin{tabular}{|c|c|c|c|c|c|c|c|c|}
\hline \multirow[b]{2}{*}{ Item $^{1}$} & \multicolumn{2}{|c|}{$B G$} & \multicolumn{6}{|c|}{ TMI } \\
\hline & $\begin{array}{c}\text { Population } 1, \\
\text { scenarios } \\
\text { I to IV }\end{array}$ & $\begin{array}{c}\text { Population } 2, \\
\text { scenarios } \\
\text { I to IV }\end{array}$ & $\begin{array}{l}\text { Population 1, } \\
\text { scenario I, no } \\
\text { cooperation }\end{array}$ & $\begin{array}{l}\text { Population } 1, \\
\text { scenarios II to } \\
\text { IV }, \text { cooperation }\end{array}$ & $\begin{array}{c}\text { Population 2, } \\
\text { scenario I, no } \\
\text { cooperation }\end{array}$ & $\begin{array}{c}\text { Population } 2, \\
\text { scenario II, }^{2} \\
\text { cooperation }^{2}\end{array}$ & $\begin{array}{l}\text { Population 2, } \\
\text { scenario III, } \\
\text { cooperation }^{2}\end{array}$ & $\begin{array}{c}\text { Population 2, } \\
\text { scenario IV, } \\
\text { cooperation }^{2}\end{array}$ \\
\hline PY & $202(29)$ & $570(55)$ & $202(29)$ & $202(29)$ & $570(55)$ & $570(55)$ & $570(55)$ & $300(39)$ \\
\hline MA & $315(44)$ & & $315(44)$ & $315(44)$ & & & & \\
\hline SCS & $0(0)$ & $166(16)$ & $0(0)$ & $0(0)$ & $166(16)$ & $166(16)$ & $166(16)$ & $166(22)$ \\
\hline $\mathrm{CF}$ & $45(6)$ & & $45(6)$ & $45(6)$ & & & $69(7)$ & $69(9)$ \\
\hline FL & $105(15)$ & & $105(15)$ & $105(15)$ & & & $162(16)$ & $162(21)$ \\
\hline
\end{tabular}

${ }^{1} \mathrm{PY}=$ protein yield; $\mathrm{MA}=$ mastitis resistance $\mathrm{DPR}=$ daughter pregnancy rate; $\mathrm{NI}=$ number of inseminations; $\mathrm{CF}=\mathrm{days}$ from calving to first insemination; $\mathrm{FL}=$ days from first to last insemination.

${ }^{2}$ Each population can use up to 9 foreign proven bulls.

initial phenotypic variances were set to 1 . The initial genetic means of the 2 populations were assumed to be the same in both simulated populations for all traits.

\section{Genetic and Phenotypic Parameters}

The genetic and phenotypic parameters for the 12 traits are given in Table 1. Genetic and phenotypic parameters within populations and genetic correlations between the same traits across populations were obtained from a comprehensive literature study. The majority of the genetic correlations between one trait in population 1 and another trait in population $2\left(r_{1,1: 2,2}\right)$ were calculated by means of the following equation:

$$
r_{1,1 ; 2,2}=\frac{r_{1,1 ; 1,2} \times r_{1,2 ; 2,2}+r_{2,1 ; 2,2} \times r_{1,1 ; 2,1}}{2}
$$

where $r_{1,1 ; 1,2}$ is the genetic correlation between trait 1 in population 1 and population $2, r_{1,2 ; 2,2}$ is the genetic correlation between trait 1 and trait 2 within population $2, r_{2,1: 2,2}$ is the genetic correlation between trait 2 in population 1 and population 2 , and $r_{1,1 ; 2,1}$ is the genetic correlation between trait 1 and trait 2 within population 1 . The genetic correlations between the udder health traits in population 1 and protein yield in population 2 were supported by a study by Rogers et al. (1998). Furthermore, the genetic correlations between the different fertility traits in populations 1 and 2 were supported by studies by Jorjani $(2005,2006 a)$.

The calculations of phenotypic correlations across populations were based on genetic correlations across populations, and the square root of the heritabilities assuming residual correlations were zero. Both the genetic and the phenotypic correlation matrices are positive definite.

\section{Scenarios for Exchange of Genetic Material}

To address the impact of selection within populations versus selection across populations, we studied the case in which the index weights in the total merit indices were the same as the economic values in the breeding goals, and the animals were selected exclusively within their own population (scenario I, Table 2).

Scenario II was supposed to reflect the current situation in the Nordic countries and in the United States. Thus, the index weights were the same as the economic values, and the populations could exchange genetic material (up to 9 foreign proven bulls could be selected; Table 2). This limit on exchange was set to avoid the unrealistic situation in the 2 populations in which more than $60 \%$ of the proven bulls could be foreign. The effect of this restriction was that the results might not show the full benefit of exchange of genetic material, but might show the benefit obtainable in a realistic situation under Nordic breeding conditions.

The impact of uniform definitions of the fertility traits were studied in a scenario in which NI, CF, and FL were included in the fertility indices for both populations and in which exchange of genetic material was possible (scenario III). For population 1, all index weights were the same as the economic values (Table 2). For population 2 , the index weights assigned to production and udder health were the same as the economic values, but the index weight assigned to fertility was divided among the traits NI, CF, and FL. Thus, in scenario III the total merit index did not correspond to the breeding goal for population 2 . The relative weighting within the fertility index corresponded to the relative weighting within the fertility index for population 1 .

To address the impact of a more similar relative weighting of the index traits across populations, we studied the case in which the index weight assigned 
to the production index was decreased for population 2 and the populations could exchange genetic material (scenario IV). For population 1, all index weights were the same as the economic values (Table 2). For population 2 , the index weight assigned to production was decreased compared with the economic value, the index weight assigned to udder health was the same as the economic value, and the index weight assigned to fertility was divided among the traits NI, CF, and FL. That is, in scenario IV the total merit index did not correspond to the breeding goal for population 2 . The relative weighting was also changed because of the changed index weight assigned to production (Table 2). As in scenario III, the relative weighting within the fertility index corresponded to the relative weighting within the fertility index for population 1.

\section{Breeding Value Estimation}

Breeding values were calculated separately for production, udder health, and fertility traits. Within these trait groups, breeding values were calculated using a multitrait and multicountry linear animal model by using the following model:

$$
y_{i, m}=h y s_{i}+a_{i, m}+e_{i, m},
$$

where $y_{i, m}$ is the record on animal $m$ for trait $i$, hys $s_{i}$ is the herd-year-season effect for each trait, and $a_{i, m}$ and $e_{i, m}$ represent the additive genetic and residual terms for trait $i$ of animal $\mathrm{m}$. This is done using the following (co)variance structure to predict breeding values:

$$
\left(\begin{array}{l}
\mathbf{a} \\
\mathbf{e}
\end{array}\right) \sim N\left(\mathbf{0} ; \quad\left[\begin{array}{cc}
\mathbf{G}_{\mathbf{0}} \otimes \mathbf{A} & \mathbf{0} \\
\mathbf{0} & \mathbf{R}_{\mathbf{0}} \otimes \mathbf{W}
\end{array}\right]\right) .
$$

The matrix $\mathbf{A}$ was the numerator relationship matrix among all animals in both populations, and the matrix W was a diagonal matrix containing ones for cows and a weight for bulls. The weight was calculated as one divided by the variance of twice the daughter group deviation (see below). The matrix $\mathbf{W}$ was used instead of an identity matrix to include bulls, whose observations were twice the daughter group deviation, in the same model as the cows in the breeding population. In all scenarios, $\mathbf{G}_{\mathbf{0}}$ and $\mathbf{R}_{\mathbf{0}}$ were $2 \times 2$ matrices for the analyses of protein yield in populations 1 and 2 , and they were $3 \times 3$ matrices for the analyses of mastitis resistance and SCS in population 1 and SCS in population 2. In scenarios I and II, $\mathbf{G}_{0}$ and $\mathbf{R}_{0}$ were $4 \times 4$ matrices for the analyses of NI, CF, and FL in population 1 and DPR in population 2. In scenarios III and IV, $\mathbf{G}_{\mathbf{0}}$ and $\mathbf{R}_{\mathbf{0}}$ were $6 \times 6$ matrices for the analyses of
NI, CF, and FL in populations 1 and 2 . The variance components used to predict breeding values were the same as those used to simulate the data. The use of covariances across populations was necessary to assign breeding values for both environments to all animals. This method can be compared with the MT-MACE method used by Interbull (Sullivan et al., 2005; Mark and Sullivan, 2006). However, the international genetic evaluations provided by Interbull are based on national genetic evaluations, whereas all genetic evaluations in this study are based on phenotypes. The breeding value prediction was carried out using the DMU package (Madsen and Jensen, 2008).

For progeny-tested sires, scaled observations (twice the daughter group deviations) were simulated multivariately, taking into account all genetic and residual covariance parameters. The mean of twice the daughter group deviation was the true breeding value of the sire, and the variance $\left(\sigma_{2 D Y D}^{2}\right)$ was calculated using the following equation:

$$
\sigma_{2 D Y D}^{2}=\frac{4 \times\left[0.75 \times \sigma_{a(B P)}^{2}+\sigma_{e(B P)}^{2}\right]}{n},
$$

where $n$ is the number of daughters with registrations for the trait, $\sigma_{a(B P)}^{2}$ is the genetic variance in the breeding population, and $\sigma_{e(B P)}^{2}$ is the residual variance in the breeding population. The variance of twice the daughter group deviation expresses the noise that is introduced through the breeding values of the dams of the first-crop daughters, Mendelian sampling, and residual variance in the phenotype of the individual first-crop daughter.

The EBV for the individual traits were weighted with the index weights given in Table 2. Each animal was assigned a total merit index for both environments that provided the basis for selection.

Progress in aggregate genotype and the traits contributing to the aggregate genotype was quantified; in this context, the aggregate genotype is a weighted sum of true breeding values and economic values. To avoid the effects of the base populations and the first years of the simulations, only data from yr 8 to 25 were used in the analyses of genetic progress because visual inspection of the results suggested that the breeding scheme was in approximate equilibrium from yr 8 with regard to the Bulmer effect, generation interval, rate of inbreeding, and rate of total genetic gain. A 2-sided alternative hypothesis was used to test for differences between all traits in scenarios I and II. Differences between protein yield, mastitis resistance, and SCS in scenarios II, III, and IV were tested using a 2-sided alternative hypoth- 
Table 3. Average regression coefficients of mean aggregate genotype in genetic standard deviation units of the true breeding goal on year of birth for each of the 4 scenarios $^{1}$

\begin{tabular}{lcccc}
\hline Item & Scenario I & Scenario II & Scenario III & Scenario IV \\
\hline Population 1 & 0.244 & 0.258 & 0.259 & 0.260 \\
Population 2 & 0.301 & 0.294 & -2 & - \\
\hline
\end{tabular}

${ }^{1}$ The standard errors were 0.004 for population 1 and in the range of 0.002 to 0.005 for population 2 .

${ }^{2}$ The average regression coefficients are not shown because the total merit indices do not correspond with the breeding goal in these scenarios.

esis, whereas differences between the fertility traits in scenarios II, III, and IV were tested using a one-sided alternative hypothesis, with the expectation of higher progress in fertility when the number of the scenario increased. In addition, the exchange of genes across populations and inbreeding were monitored.

\section{Breeding Goals}

The breeding goal of population 1 consisted of production, udder health, and female fertility expressed in environment 1 , and the breeding goal of population 2 included the same traits expressed in environment 2. Because of $\mathrm{G} \times \mathrm{E}$ interactions, these traits were seen as different traits in each environment. The abovementioned breeding goals are simplified compared with the ones used in the Nordic countries and the United States. However, these traits all have considerable economic value. Some breeding goal traits (especially functional traits) are difficult to record directly and require several measures. To imitate this situation, up to 6 index traits were chosen within each population as indicators of the breeding goal traits. The economic values given to the breeding goal traits in populations 1 and 2 corresponded to the economic values used in the Danish selection S-index before October 15, 2008 (Danish Cattle Federation, 2006), and the US Lifetime Net Merit index (VanRaden, 2006), respectively. In the simulation program, all economic values were expressed in US dollars per phenotypic standard deviation, and the values were the same in all scenarios within a population (Table 2). In the Results section, the average regression coefficients of mean aggregate genotype on year of birth are presented in genetic standard deviation units of the true breeding goal so that the coefficients are comparable across populations.

\section{Correlations Between Total Merit Indices}

The correlation between total merit indexes 1 and 2 was calculated on the basis of the parameters in Table 1 and the index weights per genetic standard deviation that belonged to the 2 indices in question.
The correlations between total merit indices were calculated using the following equation:

$$
r_{1,2}=\frac{\mathbf{b}_{1}{ }^{\prime} \mathbf{G} \mathbf{b}_{2}}{\sqrt{\mathbf{b}_{1}{ }^{\prime} \mathbf{G} \mathbf{b}_{1} \mathbf{b}_{2}{ }^{\prime} \mathbf{G} \mathbf{b}_{2}}}
$$

where the vector $\mathbf{b}_{1}$ contains the index weights of population 1 , and the vector $\mathbf{b}_{2}$ contains the index weights of population 2 (Table 2 ). The matrix $\mathbf{G}$ is the genetic correlation matrix (Table 1 ).

\section{RESULTS}

Population 1 had significantly lower progress in the aggregate genotype than population 2 across all scenarios (Table 3). Scenario I, in which exchange of genetic material was not possible, led to the lowest progress in the aggregate genotype for population 1 , and scenarios II, III, and IV were all significantly better than scenario I. The 3 scenarios in which exchange of genetic material was possible were not significantly different from each other for population 1. For population 2, scenarios I and II were not significantly different from each other, and the small difference between the scenarios was due to the application of a stochastic simulation program (i.e., due to chance).

All scenarios in which exchange of genetic material was possible led to large improvements in protein yield in population 1 , and these scenarios were significantly better than scenario I (Table 4). Altogether, scenarios I and IV tended to give higher genetic progress in udder health than scenarios II and III; however the differences were not significant. All scenarios led to declines in genetic merit for female fertility, but scenario I resulted in a significantly smaller decline in $\mathrm{CF}$ than the 3 other scenarios, and the tendency was the same for the other fertility traits. For NI and FL, scenario IV tended to be better than scenarios II and III but the differences were not significant. The genetic declines for $\mathrm{CF}$ in scenarios III and IV were 26 and $12 \%$ larger than in scenario II.

Scenarios I and III led to the greatest genetic progress in protein yield for population 2 (Table 5). Scenario 
Table 4. Average regression coefficients (ARC) of genetic values for the 6 traits registered in population 1 on year $^{1}$

\begin{tabular}{lcccc}
\hline Item $^{2}$ & Scenario I & Scenario II & Scenario III & Scenario IV \\
\hline PY & $0.217^{\mathrm{B}}$ & $0.242^{\mathrm{A}}$ & $0.243^{\mathrm{A}}$ & $0.233^{\mathrm{A}}$ \\
MA & 0.050 & 0.036 & 0.039 & 0.052 \\
SCS & 0.062 & 0.049 & 0.052 & 0.062 \\
NI & -0.069 & -0.080 & -0.079 & -0.074 \\
CF & $-0.020^{\mathrm{B}}$ & $-0.034^{\mathrm{A}}$ & $-0.043^{\mathrm{A}}$ & $-0.038^{\mathrm{A}}$ \\
FL & -0.034 & -0.042 & -0.052 & -0.037 \\
\hline
\end{tabular}

${ }^{\mathrm{A}}$ The ARC in question is significantly different from the ARC of scenario I $(P<0.05)$.

${ }^{\mathrm{B}}$ The ARC in question is significantly different from the ARC of scenario II $(P<0.05)$.

${ }^{1}$ Standard errors of ARC were in the range of 0.004 to 0.009 .

${ }^{2} \mathrm{PY}=$ protein yield; $\mathrm{MA}=$ mastitis resistance; $\mathrm{NI}=$ number of inseminations; $\mathrm{CF}=$ days from calving to first insemination; $\mathrm{FL}=$ days from first to last insemination.

IV led to significantly less genetic progress in protein and significantly greater genetic progress in SCS than the 3 other scenarios. All scenarios led to declines in genetic merit for female fertility, but scenario IV gave the smallest significant decline in NI and FL, and the other fertility traits followed that tendency. Scenario II was also significantly better than scenario I for DPR, and the tendency was the same for the other fertility traits.

The proportion of animals sired by domestic bulls and the average breed contribution of the domestic breed in each of the 2 populations are shown in Tables 6 and 7 for the scenarios in which exchange of genetic material was possible.

Selection across populations took place when it was possible, but population 1 used gradually more of its own bulls (Table 6). This is an effect of the differences between the breeding goals. On the basis of the correlation between selection indices (Table 8), it was expected that more genetic material would be exchanged in scenario IV than in scenarios II and III. However, the scenarios were not significantly different from each other. The proportion of foreign genes increased over the years at a declining rate, and equilibrium seemed to be reached in the last 2 generations in all scenarios.
After 25 yr of selection, population 2 relied almost exclusively on its own bulls in all scenarios (Table 7). Initially, exchange of genetic material took place between the 2 populations, but as the populations diverged, gene flow across populations decreased. As in the case of population 1 , there was no significant difference among the 3 scenarios regarding the proportion of animals sired by foreign bulls. The proportion of foreign genes was relatively stable over the years, and equilibrium seemed to be reached in the early generations.

The increase in inbreeding was highest for scenario I (Figure 1). This was expected because the proven bulls were selected from a much smaller group of animals. The increase in inbreeding was lowest in scenarios II and III. This corresponds to the scenarios in which the proportion of animals sired by foreign bulls and the proportion of foreign genes were highest. Very high levels of inbreeding were obtained in yr 25 in all scenarios. Although matings between half-sibs or more related animals were not allowed, long-term inbreeding was not controlled in the simulation program (e.g., by optimal contribution selection). Within each scenario, the average level of inbreeding was at the same level in populations 1 and 2, and the development showed

Table 5. Average regression coefficients (ARC) of genetic values for the 6 traits registered in population 2 on year $^{1}$

\begin{tabular}{lcccc}
\hline Item $^{2}$ & Scenario I & Scenario II & Scenario III & Scenario IV \\
\hline PY & $0.298^{\mathrm{B}}$ & $0.284^{\mathrm{A}}$ & $0.296^{\mathrm{B}}$ & $0.266^{\mathrm{A}, \mathrm{B}}$ \\
SCS & -0.012 & 0.005 & -0.012 & $0.037^{\mathrm{A}, \mathrm{B}}$ \\
DPR & $-0.070^{\mathrm{B}}$ & $-0.048^{\mathrm{A}}$ & -0.070 & $-0.035^{\mathrm{A}}$ \\
NI & -0.104 & -0.087 & -0.103 & $-0.069^{\mathrm{A}, \mathrm{B}}$ \\
CF & -0.075 & -0.064 & -0.078 & $-0.051^{\mathrm{A}}$ \\
FL & -0.120 & -0.101 & -0.113 & $-0.078^{\mathrm{A}, \mathrm{B}}$ \\
\hline
\end{tabular}

${ }^{\mathrm{A}}$ The ARC in question is significantly different from the ARC of scenario I $(P<0.05)$.

${ }^{\mathrm{B}}$ The ARC in question is significantly different from the ARC of scenario II $(P<0.05)$.

${ }^{1}$ Standard errors of ARC were in the range of 0.003 to 0.008 .

${ }^{2} \mathrm{PY}=$ protein yield; $\mathrm{DPR}=$ daughter pregnancy rate; $\mathrm{NI}=$ number of inseminations; $\mathrm{CF}=$ days from calving to first insemination; $\mathrm{FL}=$ days from first to last insemination. 


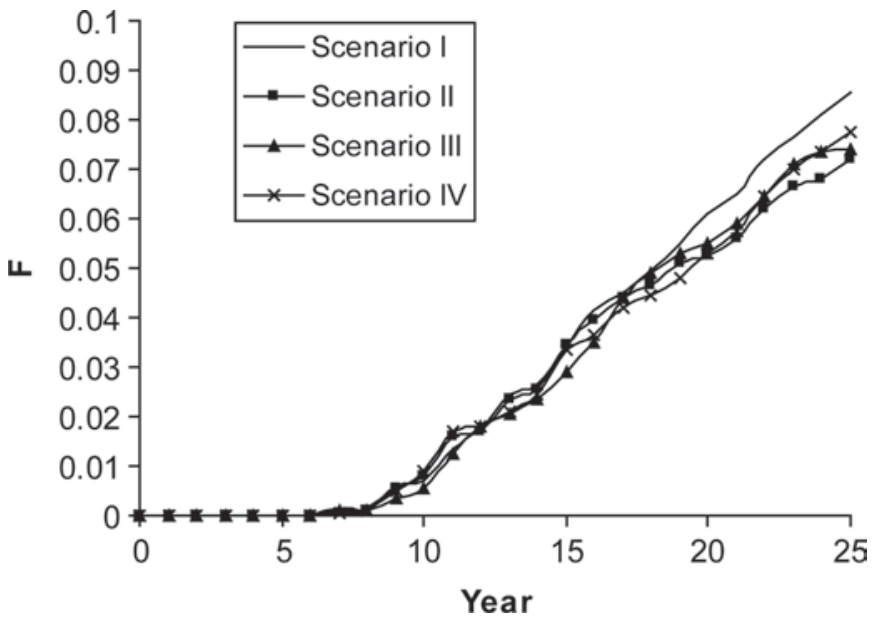

Figure 1. Average level of inbreeding in population 1 over 15 replicates for the 4 scenarios.

the same tendency (i.e., the increase in inbreeding was highest for scenario I; results not shown).

The correlation between total merit indices was about the referenced break-even correlation for profitable cooperation in all scenarios (Smith and Banos, 1991; Mulder and Bijma, 2006; Table 8). However, the correlation between total merit indices did not increase when the same fertility traits were registered in both populations (scenarios II and III). The reason could be that protein yield and DPR were less correlated than protein yield and NI, CF, and FL. The correlation between total merit indices increased (from 0.81 to 0.84 ) when the relative weighting was more similar (scenarios III and IV). The correlation between fertility indices increased when the same fertility traits were recorded in both populations, and it was higher than the correlation between total merit indices in all scenarios.

\section{DISCUSSION}

This study showed that the possibility for exchanging genetic material increased the genetic progress in a realistic dairy cattle situation. However, this effect was largest and only significant for the smallest of the populations studied here. The reason is likely that selection intensity increased more in population 1 than in population 2 because of the smaller population size.

It was expected that a standardization of the trait definitions would have a positive influence on the possibility of exchanging genetic material, and thus on progress in the aggregate genotype. However, uniform definitions of the female fertility traits in populations 1 and 2 did not increase total genetic gain in population 1 compared with a situation in which the definitions of the female fertility traits were not standardized across populations. The reason may be that the possibility of exchanging genetic material is of greater importance for a small population, such as population 1, than the similarity of the selection indices. If this is the case, then it would be in accordance with the results of Smith and Banos (1991), who found that it is better for a small population to cooperate with a large population than to operate individually, even though the breeding goals differ to some degree.

It was assumed that consumers in the future will become even more interested in sustainable food production and pay more attention, for example, to the use of antibiotics and to animal health and welfare (Olesen et al., 2000; Nielsen et al., 2006). If the public opinion toward animal production and social aspects is taken into consideration when economic values are derived, then the relative emphasis on functional traits will increase (Nielsen et al., 2006). Scenario IV was created with these concerns in mind. A more similar relative weighting of the index traits across populations did not increase total genetic gain in population 1 compared with a situation in which the definitions of the female fertility traits and the relative weighting were not standardized. The reason is probably the same as described above; hence, the possibility of exchanging genetic material is of greater importance for a small population than the similarity of the selection indices as long as the selection indices are reasonably similar.

Both populations selected animals across populations in the scenarios in which it was possible. However, the

Table 6. Proportion of animals in population 1 sired by domestic bulls (Proportion) and average breed contribution $(\mathrm{ABC})$ of the domestic breed in population 1 for the 3 scenarios in which exchange of genetic material was possible ${ }^{1}$

\begin{tabular}{lcccccccc}
\hline & \multicolumn{2}{c}{ Scenario II } & & \multicolumn{2}{c}{ Scenario III } & & \multicolumn{2}{c}{ Scenario IV } \\
\cline { 2 - 3 } \cline { 8 - 9 } \cline { 8 - 9 } Years & Proportion & ABC & & Proportion & ABC & & Proportion & \multirow{2}{*}{ ABC } \\
\hline 6 to 10 & 0.56 & 0.64 & & 0.58 & 0.67 & & 0.64 & 0.70 \\
11 to 15 & 0.63 & 0.54 & & 0.66 & 0.61 & & 0.69 & 0.66 \\
16 to 20 & 0.67 & 0.48 & & 0.75 & 0.57 & & 0.78 & 0.64 \\
21 to 25 & 0.82 & 0.47 & & 0.80 & 0.54 & & 0.85 & 0.63 \\
Mean & 0.67 & 0.53 & & 0.70 & 0.60 & & 0.74 & 0.66 \\
\hline
\end{tabular}

${ }^{1}$ Standard errors of Proportion were in the range 0.10 to 0.17 , and standard errors of $\mathrm{ABC}$ were in the range 0.07 to 0.20 . 
Table 7. Proportion of animals in population 2 sired by domestic bulls (Proportion) and average breed contribution $(\mathrm{ABC})$ of the domestic breed in population 2 for the 3 scenarios in which exchange of genetic material was possible ${ }^{1}$

\begin{tabular}{lcccccccc}
\hline & \multicolumn{2}{c}{ Scenario II } & & \multicolumn{2}{c}{ Scenario III } & & \multicolumn{2}{c}{ Scenario IV } \\
\cline { 2 - 3 } Years & Proportion & ABC & & Proportion & ABC & & Proportion & \multirow{2}{*}{ ABC } \\
\hline 6 to 10 & 0.85 & 0.84 & & 0.83 & 0.83 & & 0.80 & 0.82 \\
11 to 15 & 0.93 & 0.83 & & 0.93 & 0.80 & & 0.90 & 0.79 \\
16 to 20 & 0.95 & 0.84 & & 0.95 & 0.79 & & 0.94 & 0.80 \\
21 to 25 & 0.97 & 0.83 & & 0.97 & 0.79 & & 0.95 & 0.80 \\
Mean & 0.92 & 0.84 & & 0.92 & 0.80 & & 0.90 & 0.80 \\
\hline
\end{tabular}

${ }^{1}$ Standard errors of Proportion were in the range of 0.03 to 0.07 , and standard errors of $\mathrm{ABC}$ were in the range of 0.04 to 0.11 .

populations operated more individually over time because the correlations between selection indices were less than unity. The results of Banos and Smith (1991) showed the same development when the correlation between selection indices was low $(<0.80)$. If the correlation between selection indices is sufficiently high, an equilibrium may be reached in which the proportion of bulls selected from the foreign population stays constant (Smith and Banos, 1991). Equilibrium was not obtained within the first $25 \mathrm{yr}$ of selection for either of the simulated populations, and it is not possible to conclude whether equilibrium with exchange of semen would have been reached in the long term.

If 2 populations have identical breeding goals but different genetic means, then more animals will be selected from the superior population (Smith and Banos, 1991). Population 1 had a higher genetic mean for breeding goal 1 than population 2 and a lower genetic mean for breeding goal 2 than population 2 in all scenarios after $25 \mathrm{yr}$ of selection (results not shown). The difference between the genetic means for breeding goal 1 in populations 1 and 2 was, however, smaller than the difference between the genetic means for breeding goal 2 in populations 1 and 2 . This explains why population 1 used a higher proportion of foreign bulls than population 2 after $25 \mathrm{yr}$ of selection. The average breed contribution of the foreign breed increased over time in population 1 because the foreign genes continued to enter population 1 and because they were selectively maintained in the population. In the first years of the simulations, population 2 had not obtained a higher genetic mean for breeding goal 2 than population 1, and it was mere chance whether a superior animal was allocated to population 1 or population 2. For these reasons, population 2 imported more genetic material from population 1 in the first years of the simulation. The proportion of foreign genes in population 2 was relatively stable over the years because the foreign genes entered population 2 in the first years of the simulation and were maintained in the population.

Selection across populations is characterized by always being at least as good as selection within populations (Smith and Banos, 1991). The possibility of profitable cooperation depends, among other things, on population size. Genetic gain increases with the number of bulls tested, but at a declining rate (Smith, 1981). Consequently, the small population (in this case population 1) gained more from combining with the large population than the large population gained from combining with the small population. Population 2 obtained, in addition, greater progress in the aggregate genotype than population 1 across all scenarios, both because of the large population size and because relatively more emphasis was given to high heritability traits in population 2 than in population 1 . It was not possible to quantify the individual effect of these 2 causes in this study, but the effect of population size was also seen in scenario IV, in which lower weight was given to protein yield. It was assumed that correlations between selection indices about or above 0.80 would be sufficient to secure cooperation between the 2 populations and increase progress in the aggregate genotype. The results showed, however, that only population 1 profited by importing genetic material. Smith and Banos (1991) found that small populations benefited from cooperation at lower correlations between selec-

Table 8. Correlations between the total merit indices and correlations between the fertility indices used in population 1 and 2 in the 4 scenarios

\begin{tabular}{lcccc}
\hline Item & Scenario I & Scenario II & Scenario III & Scenario IV \\
\hline Total merit index & 0.806 & 0.806 & 0.805 & 0.840 \\
Fertility index & 0.817 & 0.817 & 0.854 & 0.854 \\
\hline
\end{tabular}


tion indices than did large populations. This indicates that the correlation between selection indices should have been higher for population 2 to benefit from the exchange of genetic material.

The means and variances of the 2 populations are, in addition to population size and the correlation between selection indices, important variables when the possibility of profitable selection across populations is considered. In this study, the initial genetic means were the same in the 2 populations. This assumption seems reasonable because the genetic levels of the traits evaluated by Interbull do not differ considerably between the 2 Holstein populations (Nielsen, 2007a,b). The reason might be that the same bulls have been used as sires of sons worldwide. The phenotypic variance of each trait was set to 1 in the base populations. Thus, the genetic variance of each trait will differ between the 2 populations because of differences in heritabilities. If the genetic variance differs between populations, the more variable population is more likely to produce superior animals. The effect of different genetic variances in the 2 populations was not quantified in this study.

As mentioned above, the possibility of importing genetic material from population 2 led to significantly greater progress in the aggregate genotype in population 1. Hence, it is recommended that the Nordic Holstein population import genetic material from the US Holstein population. However, importation of genetic material from population 2 changed the relative contribution of the traits to genetic progress. Thus, the scenario in which importation was possible led to significantly higher genetic progress in protein yield than the scenario in which population 1 operated individually, but the scenario in which population 1 did not import genetic material tended to be better in terms of functional traits. These results show that cooperation with populations that test more bulls, use smaller progeny group sizes, and give more emphasis to high heritability traits influences the direction dairy cattle breeding takes in small populations. Therefore, care should be exercised in the choice of collaborators if the Nordic breeding organizations want to prioritize genetic progress in functional traits to market Nordic Holsteins as a breed with high genetic levels for functional traits.

The contribution of the traits to progress in the aggregate genotype in population 2 changed when exchange of genetic material was possible, although no significant difference in the aggregate genotype was found. Deterioration of animal health and reproduction concerns consumers and producers (Miglior et al., 2005) because it decreases animal welfare (Sandøe et al., 1999). Therefore, if progress in the aggregate genotype remains the same whether cooperation is possible or not, it must be of common interest if progress in the aggregate genotype is due to gain in functional traits such as disease resistance and fertility.

More studies have found break-even correlations in the range of 0.80 to 0.90 (Smith and Banos, 1991; Mulder and Bijma, 2006), and the correlation between selection indices is considered to be a suitable indicator of profitable cooperation (Sonesson, 2005). If this is the case, then a clear connection between the proportion of animals sired by foreign bulls, genetic progress, and the correlation between selection indices is expected. The results in this study showed no clear connection between these factors because the proportion of animals sired by foreign bulls and genetic progress were also affected by population size and genetic superiority. This indicates that the correlation between selection indices is possibly not as important as previously thought. The reason may be that most previous studies have assumed that the breeding goals contain only 1 or 2 traits, that the heritabilities are equal in all populations, and that the populations have the same size or almost the same size (e.g., Banos and Smith, 1991; Sonesson, 2005). This study shows that it is difficult to use the break-even correlation found in one study as an accurate indicator of profitable cooperation in another study, especially in studies that reflect real situations, because other factors such as population size often differ between populations.

In population 1 , the average rate of inbreeding from yr 8 to 25 ranged from $2.05 \%$ per generation to $2.45 \%$ per generation for the 4 scenarios. These are very high rates of inbreeding because the Food and Agriculture Organization of the United Nations (1998) recommends that the rate of inbreeding should not be higher than $1 \%$ per generation. The high levels of inbreeding found in this study result from truncation selection of the animals in the simulation program and few restrictions on relatedness of mates. The actual rate of inbreeding is $1.03 \%$ per generation for Danish Holsteins, so control of the future rate of inbreeding is necessary (Sørensen et al., 2005). Programs that are able to balance the increases in genetic gain and in inbreeding have been developed. Thus, breeding organizations can keep the increase in inbreeding at an acceptable rate. Figure 1 shows that exchange of genetic material between populations can decrease inbreeding within populations, but it was not possible to quantify the effect of exchanging genetic material on inbreeding across populations in this study. The correlation between selection indices of different breeding programs partly determines the extent to which they select the same bulls (Goddard, 1992). If the correlation between selection indices is equal to unity, then the breeding organizations will select the same bulls, and the genetic diversity of the global population will decrease. The correlation be- 
tween selection indices, however, will be less than unity in most cases because of different breeding goals and $\mathrm{G}$ $\times$ E interactions (Goddard, 1992). The number of common bulls among top listings in various countries has decreased over time because international evaluations have become available and because most countries have changed to broad selection indices that include functional traits as well as production traits (Miglior et al., 2005). This may indicate that the rate of inbreeding in the global Holstein population will slow down (Miglior et al., 2005). Uniform trait definitions and evaluation procedures will increase the correlation between selection indices and possibly the rate of inbreeding in the global Holstein population. However, these results indicate that the effect of uniform definitions of the female fertility traits across populations on the correlation between selection indices is minor compared with the effect of $\mathrm{G} \times \mathrm{E}$ interactions. Population 2 experienced the same rate of inbreeding as population 1 despite its larger size. This was due to the larger selection intensity applied to test bulls and proven bulls. Hence, in terms of effective population size, the populations are equally small.

\section{CONCLUSIONS}

We investigated the effects of making definitions of female fertility traits in the Nordic and the US Holstein populations uniform as well as of applying more similar relative weightings on the genetic gain achieved in the 2 cooperating populations. However, these changes, which were expected to increase total genetic gain, did not have any impact on progress in the aggregate genotype in the Nordic Holstein population. The possibility of exchanging genetic material with the US Holstein population led to significantly higher progress in the aggregate genotype in the Nordic Holstein population compared with a situation in which exchange was not possible. Hence, it is recommended that the Nordic Holstein population import genetic material from the US Holstein population. The possibility of exchanging genetic material with the Nordic Holstein population did not change progress in the aggregate genotype in the US Holstein population compared with a situation in which exchange was not possible, but it tended to give lower genetic progress in protein yield and higher genetic progress or smaller genetic declines in the functional traits. Thus, importation of genetic material from the Nordic Holstein population may reduce the deterioration of animal health and reproduction in the US Holstein population.

\section{ACKNOWLEDGMENTS}

The authors acknowledge Han Mulder (Wageningen University, the Netherlands) and Thomas Mark (Uni- versity of Copenhagen, Denmark) for helpful comments that improved the paper and for valuable discussions on this study.

\section{REFERENCES}

Banos, G., and C. Smith. 1991. Selecting bulls across countries to maximize genetic improvement in dairy cattle. J. Anim. Breed. Genet. 108:174-181.

Danish Cattle Federation. 2006. Principles of Danish Cattle Breeding. 8th ed. http://www.lr.dk/kvaeg/diverse/principles.pdf Accessed June 19, 2008.

Food and Agriculture Organization of the United Nations. 1998. Secondary guidelines for development of national farm animal genetic resources management plans: Management of small populations at risk. J. A. Woolliams, G. P. Gwaze, T. H. E. Meuwissen, D. Planchenault, J.-P. Renard, M. Thibier, and H. Wagner, ed. Food and Agriculture Organization of the United Nations. http:/ lprdad.fao.org/cgi-bin/getblob.cgi?sid=-1,50006316 Accessed June 19, 2008.

Goddard, M. E. 1992. Optimal effective population size for the global population of black and white dairy cattle. J. Dairy Sci. 75:29022911.

Hansen, M. 2004. Quantitative Genetic Analysis of Mortality in Danish Holstein Calves. PhD Thesis. The Royal Veterinary and Agricultural University, Copenhagen, Denmark.

Interbull. 2008. Interbull routine genetic evaluation for female fertility traits. http://www-interbull.slu.se/Female_fert/framesida-fert. htm Accessed June 19, 2008.

International Committee for Animal Recording. 2007. International Agreement of Recording Practices. http://www.icar.org/ Documents/Rules\%20and\%20regulations/Guidelines/ Guidelines_2007.pdf Accessed June 19, 2008.

Jørgensen, J. N., and M. K. Sørensen. 2002. Effect of cooperation between dairy cattle breeds with different breeding objectives. Page 000-000 in Proc. 7th World Congr. Genet. Appl. Livest. Prod., Montpellier, France. Commun. no. 23-23.

Jorjani, H. 2005. Interbull pilot study for female fertility traits in Holstein populations. Proceedings of the Interbull Open Meeting, Uppsala, Sweden, June 3-4, 2005. Interbull Bull. 33:34-44.

Jorjani, H. 2006a. International genetic evaluation for female fertility traits in Holstein populations. Proceedings of the Interbull Technical Meeting, Wageningen, the Netherlands, March 2-3, 2006. Interbull Bull. 34:57-64.

Jorjani, H. 2006b. International genetic evaluation for female fertility traits. Proceedings of the Interbull Meeting, Kuopio, Finland, June 4-6, 2006. Interbull Bull. 35:42-46.

Lynch, M., and B. Walsh. 1998. Genetics and Analysis of Quantitative Traits. Sinauer Associates Inc., Sunderland, MA.

Madsen, P., and J. Jensen. 2008. DMU: A User's Guide. A Package for Analysing Multivariate Mixed Models. Version 6, release 4.7. Danish Inst. Agric. Sci., Foulum, Denmark. http://dmu.agrsci.dk Accessed June 19, 2008

Mark, T., and P. G. Sullivan. 2006. Multiple-trait multiple-country genetic evaluations for udder health traits. J. Dairy Sci. 89:48744885.

Miglior, F., B. L. Muir, and B. J. Van Doormaal. 2005. Selection indices in Holstein cattle of various countries. J. Dairy Sci. 88:1255-1263.

Mulder, H. A., and P. Bijma. 2006. Benefits of cooperation between breeding programs in the presence of genotype by environment interaction. J. Dairy Sci. 89:1727-1739.

Nielsen, H. M., L. G. Christensen, and J. Ødegård. 2006. A method to define breeding goals for sustainable dairy cattle production. J. Dairy Sci. 89:3615-3625.

Nielsen, U. S. 2007a. Genetisk niveau for ydelse i forskellige lande. KvægInfo nr. 1758. Dansk Landbrugsrådgivning, Landscentret. http://www.lr.dk/kvaeg/informationsserier/lk-meddelelser/1758. htm Accessed Nov. 4, 2008. 
Nielsen, U. S. 2007b. Genetisk niveau for yversundhed i forskellige lande. KvægInfo nr. 1759. Dansk Landbrugsrådgivning, Landscentret. http://www.lr.dk/kvaeg/informationsserier/lk-meddelelser/1759. htm Accessed Nov. 4, 2008.

Olesen, I., A. F. Groen, and B. Gjerde. 2000. Definition of animal breeding goals for sustainable production systems. J. Anim. Sci. 78:570-582.

Rogers, G. W., G. Banos, U. S. Nielsen, and J. Philipsson. 1998 Genetic correlations among somatic cell scores, productive life, and type traits from the United States and udder health measures from Denmark and Sweden. J. Dairy Sci. 81:1445-1453.

Sandøe, P., B. L. Nielsen, L. G. Christensen, and P. Sørensen. 1999 Staying good while playing God-The ethics of breeding farm animals. Anim. Welf. 8:313-328.

Shook, G. E. 2006. Major advances in determining appropriate selection goals. J. Dairy Sci. 89:1349-1361.

Smith, C. 1981. Levels of investment in testing the genetic improvement of livestock. Livest. Prod. Sci. 8:193-201.

Smith, C., and G. Banos. 1991. Selection within and across populations in livestock improvement. J. Anim. Sci. 69:2387-2394.
Sonesson, A. K. 2005. Assessing total profit of alternative levels of co-operation between Nordic cattle populations. Pages 6-22 in Project Report: Sustainable Breeding in the Nordic Red Dairy Breeds Meeting, Uppsala, Sweden, October 25-26, 2005.

Sørensen, A. C., M. K. Sørensen, and P. Berg. 2005. Inbreeding in Danish dairy cattle breeds. J. Dairy Sci. 88:1865-1872.

Sørensen, M. K., P. Berg, J. Jensen, and L. G. Christensen. 1999. Stochastic simulation of breeding schemes for total merit in dairy cattle. GIFT Seminar on Genetic Improvement of Functional Traits in Cattle, Wageningen, the Netherlands, November 7-9, 1999. Interbull Bull. 23:183-192.

Sullivan, P. G., J. W. Wilton, L. R. Schaeffer, G. J. Jansen, J. A. B. Robinson, and O. B. Allen. 2005. Genetic evaluation strategies for multiple traits and countries. Livest. Prod. Sci. 92:195-205.

VanRaden, P. M. 2006. Net merit as a measure of lifetime profit: Proposed 2006 revision. http://www.aipl.arsusda.gov/reference/ nmcalc.htm Accessed June 19, 2008.

The World Holstein Friesian Federation. 2005. International type evaluation of dairy cattle. http://www.whff.info/pdf/type en_2005-2.pdf Accessed June 19, 2008. 